shows similar folds. The left gland of this female is normal. The female in which this abnormality has been found is a young one, as is evident from the small size of the ovarioles and of the accessory glands.

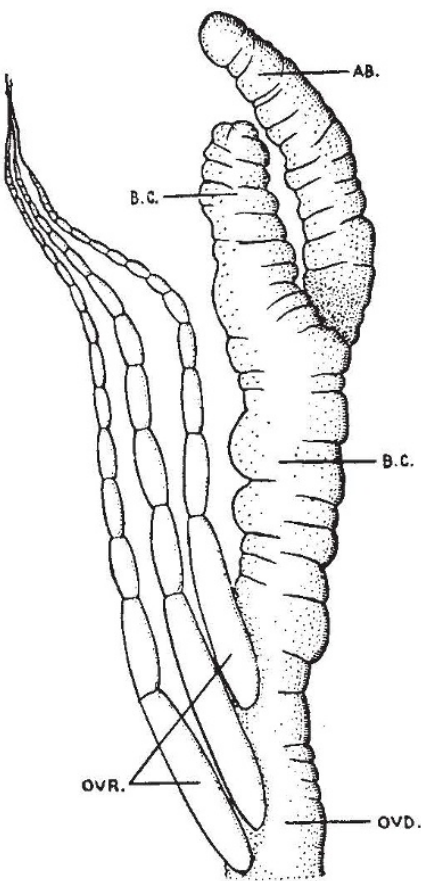

FIG. 1. The right female accessory gland of Schistocerca gregaria Forsk. showing the abnormal outgrowth. Camera lucida drawing. $\times 12 . A B$ abnormal outgrowth of the gland. $B C$, female accessory gland. $O V D$ egg-calyx; $O V R$, ovarioles.

I had previously dissected more than a hundred females of this species but never encountered any abnormality in the accessory glands; nor, so far as my knowledge goes, has such an abnormality been recorded in any other Acridiid.

Zoological Laboratory,

\section{L. RoonwaL.} Cambridge.

1 Trans. Ent. Soc. Lond., 75; 1927.

C.R. Acad. Sci., $22 ; 1896$.

3 "Locusts and Grasshoppers". London, 1928.

\section{Crown Rot of Sugar Beet a Boron Deficiency}

CRown rot of sugar beet and mangel is an unsatisfactory disease to account for, and some doubt has always attended the attribution of it to the fungus Phoma beta, Frank. It was not entirely surprising, therefore, that Brandenburg ${ }^{1}$ has recently shown in Holland that the disease is caused by boron deficiency, and can be cured by the addition of this element, in the entire absence of the fungus. This has now been confirmed in Ireland.

In the first of the present experiments, ten sugar beet seedlings were grown in Crone's solution $(p H$ $6 \cdot 2-6 \cdot 5$ ) without boron, and 20 with the addition of I mgm. of boric acid per litre. The former developed crown rot rapidly and to such an extent that, after 30 days, three of them were dead and seven seriously diseased, while the latter grew normally and much more vigorously. At this stage the experiment was reversed, boric acid being supplied to the seven seriously diseased plants and withheld from ten of the twenty healthy ones. The effect was immediate, for the former began to grow and produced secondary crowns, as in field attacks of the disease, while the latter developed crown rot. The ten plants receiving boron throughout continued to grow well to the end. Similar results were obtained using Tollens' and Knop's solutions. There was no parasitic fungus associated with the disease.

Confirmatory results were secured in two field experiments in Carlow where the disease is very severe locally. The yield and value of the crop were about doubled in one case (where the attack was exceptional) and increased by one half in the other, the sugar content being raised by 1-3 per cent, by applications of 12-20 lb. of borax per acre. Heavier applications did not appear to give proportionate increases, but the disease is very unevenly distributed and the optimum rate of application has not yet been determined. Brandenburg used about $18 \mathrm{lb}$. per acre.

The discovery has much economic importance. Thirty per cent of the beet area of Leinster is said to be subject to crown rot, and as a result of this work the incorporation of borax with the fertilisers is being considered. The addition of borax where the disease was absent showed no apparent effect, beneficial or otherwise. W. Hughes.

Department of Plant Pathology, Paul A. Murphy.

Albert Agricultural College, Glasnevin,

Dublin.

${ }^{1}$ Brandenburg, E., Phytopath. Z., 3, 499: 1931.

\section{Nomenclature of Vitamin $B_{2}$}

Perhaps it is useful to direct attention to the above subject before confusion gets worse confounded. It was pointed out in 1931 that the use of the terms vitamin $\mathrm{B}_{2}$ and anti-dermatitis (anti-pellagra ?) factor interchangeably was already causing difficulties ${ }^{1}$. The discovery by Kuhn and his co-workers that lactoflavine is able to supplement a vitamin $B_{2}$. deficient diet for the growth of rats constitutes a great advance, but the anti-dermatitis factor (the so-called Haut-faktor of the Heidelberg workers) does not appear to be identical with it. Again, we have observed ${ }^{2}$ that concentrates of renoflavine (obtained from ox-kidney extracts) have their growth-promoting effect considerably enhanced by the addition of a relatively heat- and alkali-stable substance present in ox-kidney extracts, which is not so well adsorbed by fuller's earth in acid solution as the flavine. The tests were carried out with 'vitamin B'-deficient rats receiving vitamins $B_{1}$ and $B_{2}$.

The same heat-stable factor in ox-kidney extracts, which is obviously different from vitamins $B_{1}, B_{4}$ and the flavine, has been found also to supplement the growth-promoting power of a pure preparation of lactoflavine, very kindly supplied by Prof. R. Kuhn. Apparently similar results obtained in biological experiments with lactoflavine have already been reported by Chick and Copping ${ }^{3}$; and Booher, Blogett and Page ${ }^{4}$. Elvehjem and Koehn ${ }^{5}$ now report that flavines cannot prevent 'pellagraic' symptoms in chicks, maintained on a ration low in vitamin $B_{2}$. content. That there is some factor missing in the usual vitamin $\mathrm{B}_{2}$-deficient diet, that causos cataract in rats, is indicated by the work of Langston and Day $^{6}$. We have ourselves met with cases of cataract 